\title{
Growth Process of Copper Particles in the Cuprous Oxide-Water System
}

\author{
Hoang T. Hai ${ }^{1,2}$, Ahn J. Gwan ${ }^{1, *}$, Kim D. Jin ${ }^{1}$, Jeong S. Sohn ${ }^{1}$, \\ Kim C. $\mathrm{Oh}^{2}$ and Chung H. Saeng ${ }^{1}$ \\ ${ }^{1}$ Korean Institute of Geoscience and Mineral Resources, 30 Gajung-dong, Yuseong-Gu, Daejeon 305-350, Korea \\ ${ }^{2}$ Chungnam National University, 220 Gung-dong, Yuseong-gu, Daejeon 305-764, Korea
}

Dispersed copper powder was prepared from cuprous oxide slurry by a wet chemical reduction technique with hydrazine. Palladium chloride $\left(\mathrm{PdCl}_{2}\right)$ was used to produce palladium $(\mathrm{Pd})$ seed with its stabilizer, polyvinyl pyrrolidone $(\mathrm{PVP})$ and sodium pyrophosphate $\left(\mathrm{Na}_{4} \mathrm{O}_{7} \mathrm{P}_{2}\right)$ was added as a dispersion agent. The formation and growth process of copper particles in the heterogeneous system were investigated in terms of reaction temperature and slurry concentration. As a general trend observed elsewhere, the average particle size of copper powder decreased from $420 \mathrm{~nm}$ to $150 \mathrm{~nm}$ with an increase of temperature from 313 to $353 \mathrm{~K}$, while the shape of its number particle size distribution changed from bimodal at low temperatures $(313-323 \mathrm{~K})$ to mono-modal at higher ones (333-353 K). Moreover, number size distributions of the powders produced at higher concentrations $(2.5-40 \mathrm{~g} / \mathrm{L})$ all exhibit mono-modal shape while at $1.25 \mathrm{~g} / \mathrm{L}$ it is bi-modal one. The explanation were based on the relationship between the number of Pd seed on the copper particles activated, which govern size and size distribution of final production in heterogeneous system, and the generation rate of $\mathrm{Cu}$ monomer at given conditions. [doi:10.2320/matertrans.48.1137]

(Received January 10, 2007; Accepted March 20, 2007; Published April 25, 2007)

Keywords: copper, cuprous oxide, chemical synthesis, metal, powder processing

\section{Introduction}

Conductive pastes have been used for the formation of thick film conductors such as electrodes or conductive patterns in multilayered electronic parts and printed circuit boards. They include metal powder dispersed in an organic vehicle along with glass frit. The replacement of precious metal powders like gold, silver or palladium by copper powder for the production of conductive paste for hybrid integrated circuit and for the metallization of multilayer ceramic capacitor (MLCC) is a current trend in the electronic industry. Copper offers several economic and performance advantages over precious metals. The conductivity of copper is as good as silver and $40 \%$ better than that of gold. The stability of copper at high frequencies is better than that of gold or silver and it is compatible with most solder materials. ${ }^{1)}$

A number of methods have been developed for the preparation of $\mathrm{Cu}$ powder. Among them, the chemical reduction of copper salts with hydrazine or hydrogen in an aqueous system has been well known. ${ }^{2,3)}$ However, this method suffers from agglomeration and chaotic growth of copper particles. Recently, copper oxide slurries in liquid polyols have been studied to improve the uniformity and dispersion of copper particles, but this technique requires high intensity energy and long reaction time. ${ }^{4)}$ Copper oxides slurry usually exhibits very low solubility in water, so that the replacement of solute salts by the solid oxides in wet reduction method is expected to minimize the agglomeration resulted from the strong reduction power of hydrazine or hydrogen. However, any reports to deal with the preparation of $\mathrm{Cu}$ powders from corresponding oxide compounds by a wet chemical reduction are hardly found.

In the present study, fine copper metal powders were prepared from a heterogeneous system of $\mathrm{Cu}_{2} \mathrm{O}$-water slurry by chemical reduction with hydrazine. The investigation

*Corresponding author, E-mail: dran@ rock25t.kigam.re.kr focused on the process parameters which play an important role on the stability of powder in liquid as well as its size and size distribution, such as reaction temperature and concentration of precursor.

\section{Experimental Procedure}

All chemicals used throughout the experiments are in analytical grade. Cuprous oxide $\left(\mathrm{Cu}_{2} \mathrm{O}\right)$, polyvinyl pyrrolidone (PVP k-30) and sodium pyrophosphate decahydrate $\left(\mathrm{Na}_{4} \mathrm{O}_{7} \mathrm{P}_{2} \cdot 10 \mathrm{H}_{2} \mathrm{O}\right)$ are purchased from Junsei Chemical Co., Japan. Palladium chloride $\left(\mathrm{PdCl}_{2}\right)$ was from Kojima Chemical Reagents Inc., Japan and hydrazine monohydrate $(80 \%$ $\mathrm{N}_{2} \mathrm{H}_{4} \cdot \mathrm{H}_{2} \mathrm{O}$ ) from DC Chemical Co., Korea.

In a typical procedure, $3 \mathrm{~g}$ PVP was added to a $300 \mathrm{~mL}$ $1.15 \times 10^{-5} \mathrm{M} \mathrm{Pd}^{2+}$ solution and mixed under a magnetic bar stirring condition. Stable palladium seeds $(\sim 5 \mathrm{~nm})$ as shown in Fig. 1 were formed by adding $1 \mathrm{~mL}$ hydrazine into the solution at $313 \mathrm{~K}$. This step can be understood as an attempt for achieving a short burst nucleation.

Applying the result reported by J.G. $\mathrm{Ahn}^{5)}$ a dosage of $99 \mathrm{mg} / \mathrm{L} \mathrm{Na}_{4} \mathrm{O}_{7} \mathrm{P}_{2}$, which strongly promotes zeta potential of as-formed $\mathrm{Cu}$ particles, was added into the above suspension along with an addition of $\mathrm{Cu}_{2} \mathrm{O}$ in the 1.25 to $40 \mathrm{~g} / \mathrm{L}$ range, and mixed in several ten seconds. Then, a hydrazine solution was slowly introduced drop by drop at $0.6 \mathrm{~mL} / \mathrm{min}$. The reaction temperature was varied from 313 to $353 \mathrm{~K}$. The suspension was kept under agitation in atmospheric ambient air until the reaction completes. At the termination of each reaction, the precipitated solid particles were separated and subsequently washed with distilled water and ethanol several times. Finally, the powder was dried at $313 \mathrm{~K}$ in nitrogen and kept in a desiccator to minimize oxidation.

The consumption time, which is the time required to completely convert $\mathrm{Cu}_{2} \mathrm{O}$ to $\mathrm{Cu}$ metal, was determined by Xray diffraction (XRD, RTP 300PC, Rigaku, Japan) in reflection mode $(\mathrm{Cu}-\mathrm{K} \alpha$ radiation) for the products sampled at different time intervals. The particle size distribution of $\mathrm{Cu}$ 


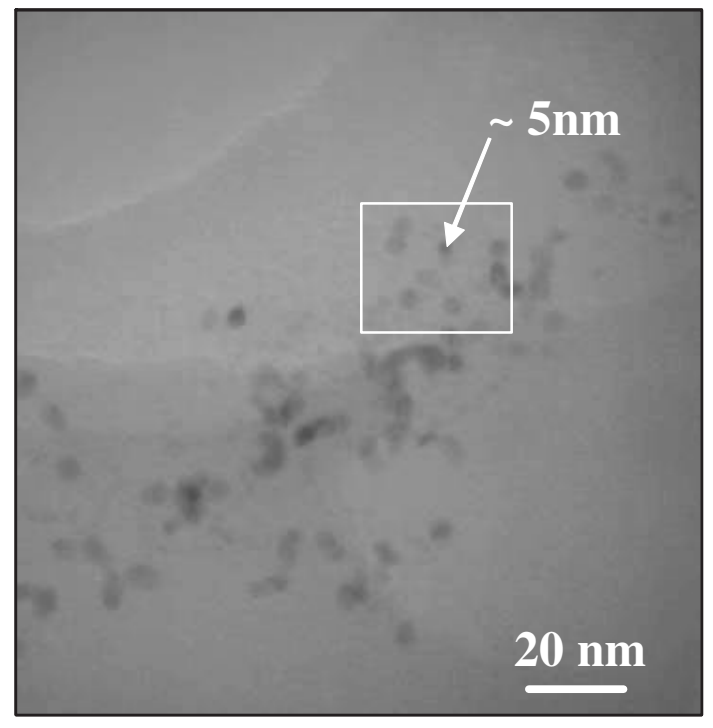

Fig. 1 TEM image of Pd seed produced in the typical procedure.

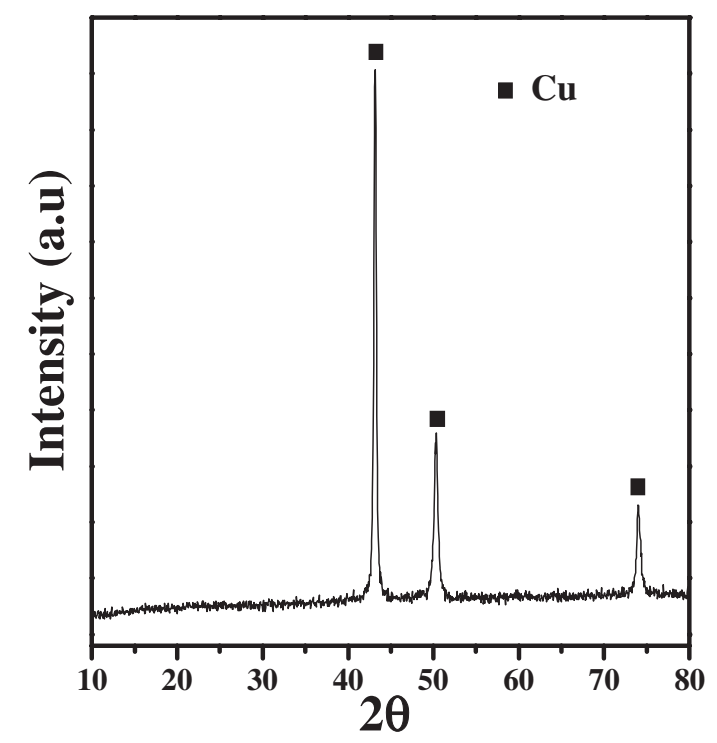

Fig. 2 XRD pattern of the $\mathrm{Cu}$ powder prepared with $10 \mathrm{~g} / \mathrm{L} \mathrm{Cu}_{2} \mathrm{O}$ at $333 \mathrm{~K}$.

powders was measured by counting 100 particles in each picture taken by scanning electron microscopy (SEM, JEOL, JPS-9010, Japan).

\section{Results and Discussion}

Figure 2 shows XRD pattern of the $\mathrm{Cu}$ powders produced in accordance with the typical procedure described in the experimental procedure: $10 \mathrm{~g} / \mathrm{L} \mathrm{Cu} \mathrm{Cu}_{2} \mathrm{O}, 99 \mathrm{mg} / \mathrm{L} \mathrm{Na} \mathrm{O}_{2} \mathrm{P}_{7}$, and $0.6 \mathrm{~mL} / \mathrm{min}$. $\mathrm{N}_{2} \mathrm{H}_{4}$ at $333 \mathrm{~K}$. The well-defined copper crystalline peaks only are detected, but no oxide compound peaks are found, confirming the complete conversion from $\mathrm{Cu}_{2} \mathrm{O}$ to $\mathrm{Cu}$.

Figure 3 shows the SEM images of $\mathrm{Cu}$ powders produced at different reaction temperatures. Apparently, the powders show spherical in shape, well dispersed as a consequence of a $99 \mathrm{mg} / \mathrm{L} \mathrm{Na} \mathrm{Na}_{7} \mathrm{P}_{2}$ addition giving rise of electrostatical repulsion. ${ }^{5)}$
Figure 4 depicts the mean size variation with reaction temperature. While the temperature varies from $313 \mathrm{~K}$ to $353 \mathrm{~K}$, the mean particle size decreases monotonically from $420 \mathrm{~nm}$ at $313 \mathrm{~K}$ down to $150 \mathrm{~nm}$ at $353 \mathrm{~K}$, meanwhile their number size distributions changes from bi-modal at $313 \mathrm{~K}$ and $323 \mathrm{~K}$ to mono-modal at higher temperatures as shown in Fig. 5.

In general, the size and size distribution of the final powder formed by heterogeneous nucleation depends closely on two variables: aggregation of formed particles and number of $\mathrm{Pd}$ seed particles. As reported by J.G. Ahn, ${ }^{5)}$ the aggregation of particles is prevented well by an addition of $99 \mathrm{mg} / \mathrm{L}$ $\mathrm{Na}_{4} \mathrm{O}_{7} \mathrm{P}_{2}$. Thus, the number of $\mathrm{Pd}$ seed particles added externally will elucidate the characteristics of the resulting products formed at different temperatures.

As mentioned above, the Pd particles used as seeds in these conditions were stabilized by PVP. It is anticipated that their surface activity might be lowered by the PVP absorption layers, thus inhibiting the deposition of $\mathrm{Cu}$ monomers on them, leading to a significant difference between the numbers of Pd particles added and the true number activated. In other words, the inactivated Pd particles can be collected conveniently after terminating the conversions. According to this way, the number of activated Pd particles can be inferred precisely. The process for collecting inactivated $\mathrm{Pd}$ seed particles is represented in the reference. ${ }^{6)}$

The total number of $\mathrm{Pd}$ particles formed from $1.5 \times 10^{-5} \mathrm{M} \mathrm{Pd}^{2+}$ addition and the number of $\mathrm{Pd}$ particles in the decanted solution are denoted as $\mathrm{N}_{T}$ and $\mathrm{N}_{R}$, respectively. The term $\frac{N_{T}-N_{R}}{N_{T}} \cdot 100 \%$ is defined as the weight percentage of $\mathrm{Pd}$ particles consumed in the $\mathrm{Cu}_{2} \mathrm{O}-\mathrm{Cu}$ conversion or the weight percentage of active $\mathrm{Pd}$ particles.

Figure 6(a) shows the weight percentage of active $\mathrm{Pd}$ particles increasing with an increase of reaction temperature in the investigated range $(313-353 \mathrm{~K})$. For instance, $22 \%$, $51 \%, 55 \%, 66 \%$ and $73 \%$ Pd particles were consumed at 313 , $323,333,343$ and $353 \mathrm{~K}$, respectively.

A rapidly decrease of consumption time resulted from an increase of reaction temperature shown in the Fig. 4 indicates a strong promotion of temperature on reaction rate. Accordingly, it is believed that at higher reaction temperature (333$353 \mathrm{~K}$ ), larger number of $\mathrm{Cu}$ monomers is generated in a short duration; hence easily deposit on the PVP-absorbed Pd particles to form primary particles, which is closely related to the high trend of decreasing surface energy. ${ }^{7)}$ Whereas they would select only the most activated Pd particles for their deposition as reaction rate is low at $313 \mathrm{~K}$ and $323 \mathrm{~K}$. In other words, at higher reaction rate conditions larger numbers of $\mathrm{Pd}$ particles were consumed. Considering on a constantly used $\mathrm{Cu}_{2} \mathrm{O}$ amount of $10 \mathrm{~g} / \mathrm{L}$, a decrease of particles size of the powders followed by an increase of temperature as shown in Fig. 3 are evident.

Figure 6(b) shows the weight percentage of active $\mathrm{Pd}$ particles as a function of reaction time at different temperatures $(313-353 \mathrm{~K})$. At $313 \mathrm{~K}$, it increases gradually from $0 \%$ to $22 \%$ until finishing the $\mathrm{Cu}_{2} \mathrm{O}-\mathrm{Cu}$ conversion after 50 minutes. Meanwhile, at $323 \mathrm{~K}$, it increases from $0 \%$ to $51 \%$ following different slopes. Firstly, it increases rapidly to $40 \%$ after 5 minutes, then gradually to $48 \%$ and $50 \%$ after 10 and 20 minutes respectively, and thereafter remains nearly 

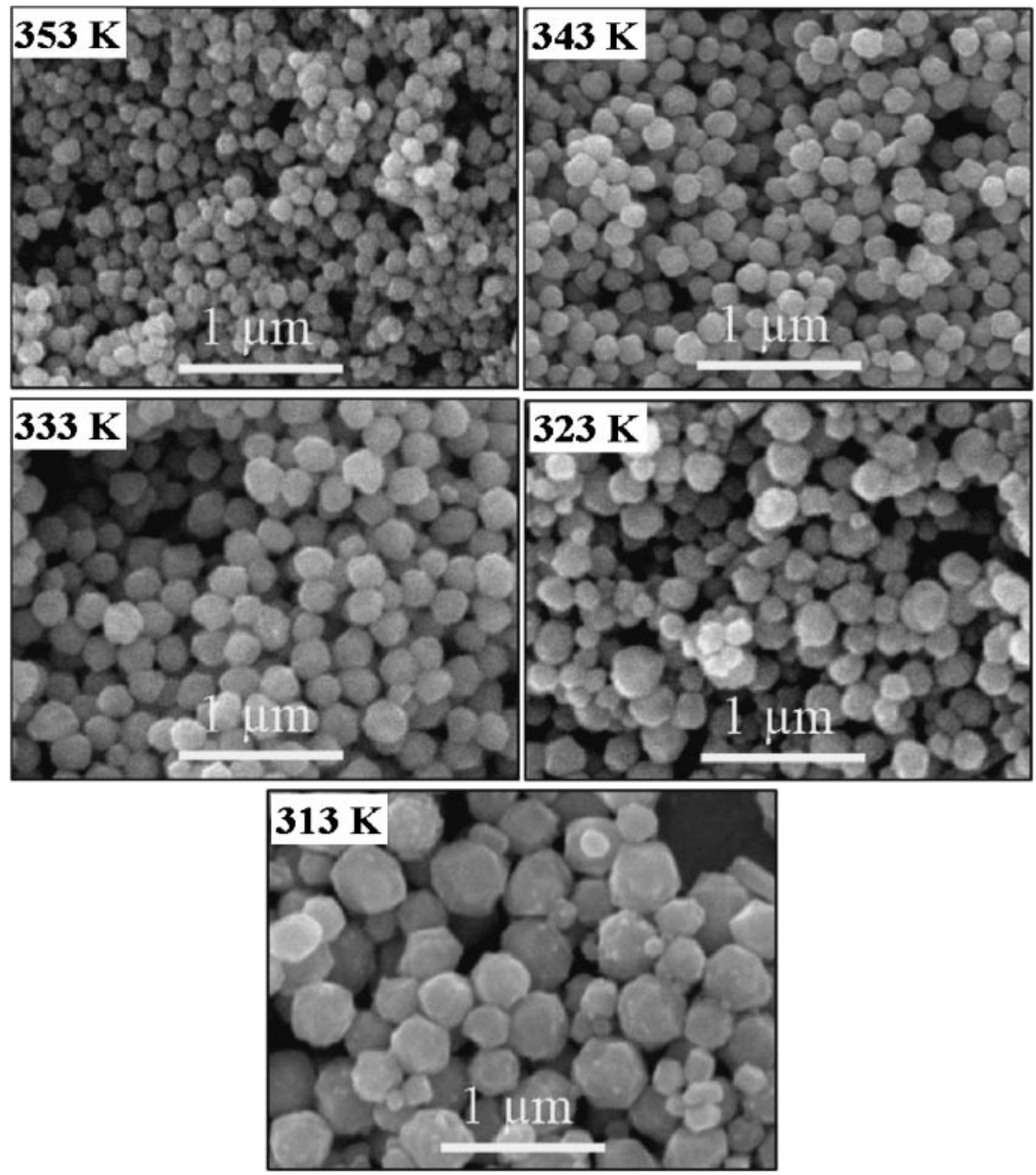

Fig. 3 SEM images of $\mathrm{Cu}$ powders prepared with $10 \mathrm{~g} / \mathrm{L} \mathrm{Cu} 2 \mathrm{O}$ at different temperatures.

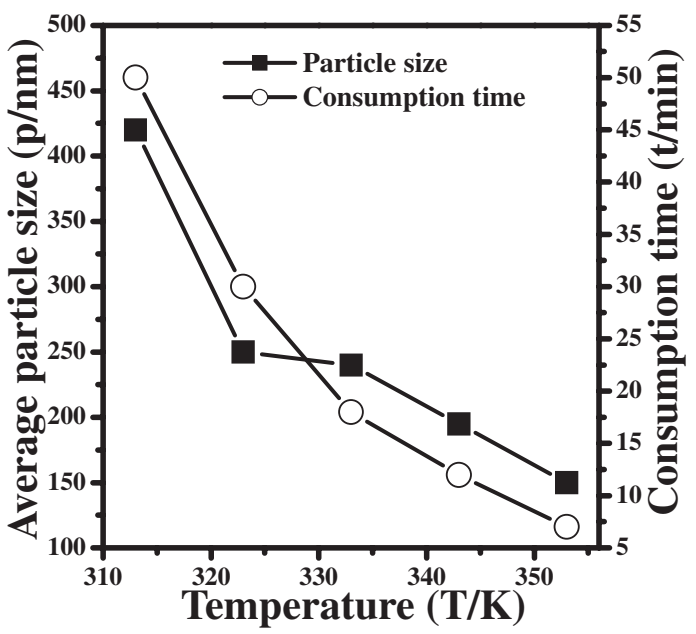

Fig. 4 Average particle sizes and consumption times as a function of temperature at $10 \mathrm{~g} / \mathrm{L} \mathrm{Cu}_{2} \mathrm{O}$.

constant throughout the rest of reaction time (30 minutes). The feature of this variation demonstrates Pd particles are first preferentially deposited with $\mathrm{Cu}$ monomers to form stable particles, but are not sufficient to consume completely

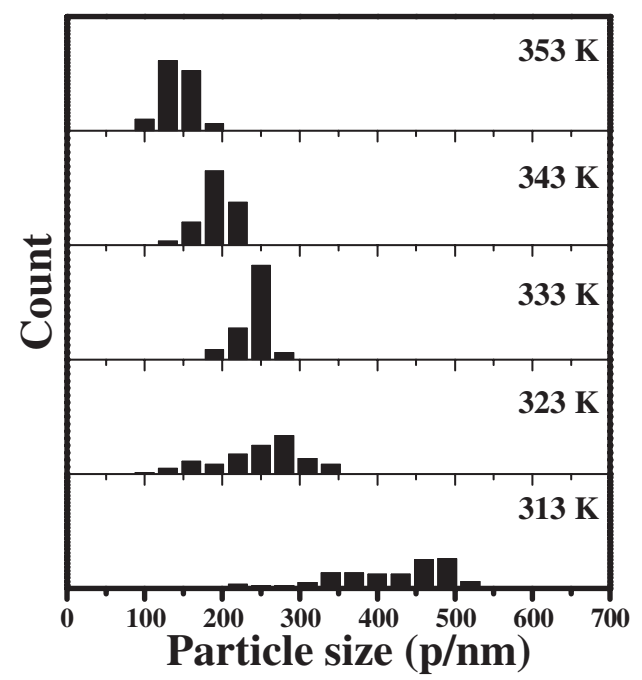

Fig. 5 Number particle size distributions at different temperatures with $10 \mathrm{~g} / \mathrm{L} \mathrm{Cu} 2 \mathrm{O}$.

a further generation of $\mathrm{Cu}$ monomers at the given condition, resulting in an accumulation of $\mathrm{Cu}$ monomers in solution, thus leading to the tendency of continuously consuming the 


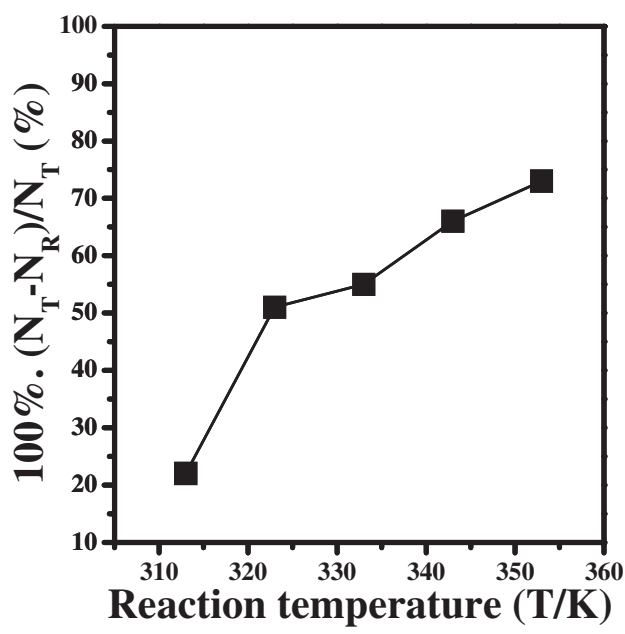

(a)

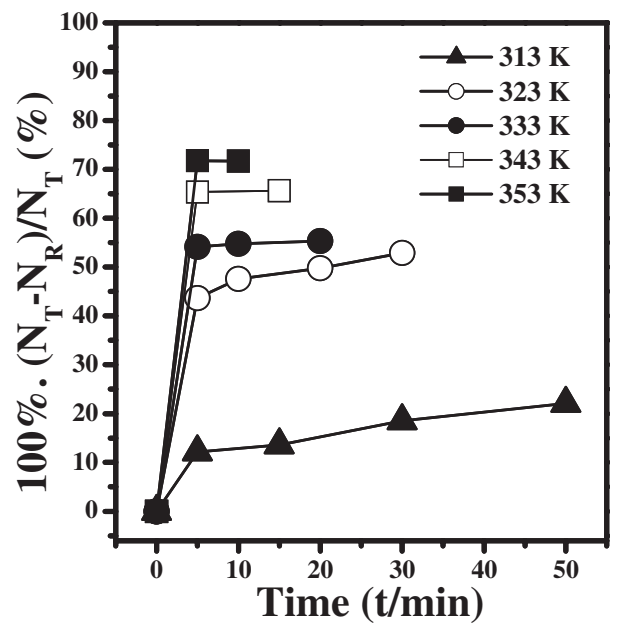

(b)

Fig. 6 Weight percentages of active palladium particles as a function of (a) reaction temperature and (b) time at different temperatures.

rest number of $\mathrm{Pd}$ particles until the balance between generation of supersaturation by the reaction and consumption rate by the particle growth was well established. ${ }^{8)}$ In this respect, it can be said that a slow consumption rate of $\mathrm{Pd}$ particles in the conversions at $313 \mathrm{~K}$ and $323 \mathrm{~K}$ seems to be like a continuous nucleation occurred in homogeneous system, evidently yielding the powder with bi-modal number particle size distribution as shown in Fig. 4.9)

In contrarily, at 333, 343 and $353 \mathrm{~K}, 55 \%, 66 \%$ and $72 \%$ $\mathrm{Pd}$ particles respectively, were quickly consumed at early stages of the conversions (after 5 minutes), and thereafter no longer Pd particles were consumed. In other words, those numbers of $\mathrm{Pd}$ particles were good enough to consume completely the further generation of supersaturation at the given condition. ${ }^{8,10-13)}$ All particles start growing at the same point of time, thus yielding mono-modal number particle size distribution powders as described in Fig. 5.

Figure 7 shows the SEM images of the $\mathrm{Cu}$ powders produced at different $\mathrm{Cu}_{2} \mathrm{O}$ concentrations $(1.25-40 \mathrm{~g} / \mathrm{L})$ at $333 \mathrm{~K}$ following the typical procedure. The powders are roughly spherical in shape and well dispersed. This proves that the electrostatical repulsion by $99 \mathrm{mg} / \mathrm{L} \quad \mathrm{Na}_{4} \mathrm{O}_{7} \mathrm{P}_{2}$ addition plays strong impact in highly concentrated slurry system.

Interestingly, the average particle size first decreases from $183 \mathrm{~nm}$ at $1.25 \mathrm{~g} / \mathrm{L} \mathrm{Cu}_{2} \mathrm{O}$ down to $178 \mathrm{~nm}$ at $2.5 \mathrm{~g} / \mathrm{L} \mathrm{Cu}_{2} \mathrm{O}$, and thereafter monotonically increases to $354 \mathrm{~nm}$ at $40 \mathrm{~g} / \mathrm{L}$ as depicted in Fig. 8. It has been known that the particle size of the copper usually increases as precursor concentration increases. ${ }^{4,14)}$ However, in the present research, this relationship seems to be no longer appropriate.

In Fig. 8, it is noticed that although $\mathrm{Cu}_{2} \mathrm{O}$ concentrations are largely different but the consumption times show a slightly deviation. It suggests that the generation rate of $\mathrm{Cu}$ monomers at high $\mathrm{Cu}_{2} \mathrm{O}$ concentrations is extremely high over than that at lower $\mathrm{Cu}_{2} \mathrm{O}$ concentrations. In this respect, impact of $\mathrm{Cu}_{2} \mathrm{O}$ concentration is same as that of temperature in promoting reaction rate, thus activity of $\mathrm{Pd}$ particles. Indeed, Fig. 9 indicates that at $1.25 \mathrm{~g} / \mathrm{L} \mathrm{Cu}_{2} \mathrm{O}$ condition $14 \%$ Pd particle were consumed, while at 2.5, 5, 10, 20, 30 and

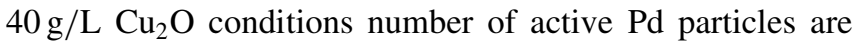
equal to $28,47,66,72,81$ and $86 \%$ respectively of the total Pd particles added externally.

As a general rule, an increase in number of active $\mathrm{Pd}$ particles usually results in a decrease of $\mathrm{Cu}$ particle size while an increase of $\mathrm{Cu}_{2} \mathrm{O}$ concentration usually results in an increase of particle size. In this respect, a decrease of particle size in the range $1.25-2.5 \mathrm{~g} / \mathrm{L}$ is due to the domination of the former over than the latter while an increase of particle size in the range $2.5-40 \mathrm{~g} / \mathrm{L} \mathrm{CC_{2 }} \mathrm{O}$ concentration is due to the domination of the latter over than the former.

As mentioned previously, generation rate of $\mathrm{Cu}$ monomers at $1.25 \mathrm{~g} / \mathrm{L} \mathrm{Cu}_{2} \mathrm{O}$ is too low as compared to the others. It is believed that that number of Pd particles is slowly consumed throughout the process. Therefore, the bi-modal number size distribution of the powder at $1.25 \mathrm{~g} / \mathrm{L}$ as shown in Fig. 10 is because $\mathrm{Pd}$ particles grown at different points of time by $\mathrm{Cu}$ monomer deposition.

In contrarily, Fig. 10 shows that all the other powders produced in the range $2.5-40 \mathrm{~g} / \mathrm{L}$ exhibit mono-modal number particle size distributions. It can be thought that the numbers of Pd particles equal to 28, 47, 66, 72, 81 and $86 \%$ might be consumed at the beginnings, are good enough to establish the balance between the generation rate of $\mathrm{Cu}$ monomers by the reaction and consumption rate by the $\mathrm{Pd}$ particles growth at 5,10,20,30, $40 \mathrm{~g} / \mathrm{L} \mathrm{Cu}_{2} \mathrm{O}$ conditions, thus yielding mono-modal number size distribution powders. ${ }^{8,10-13)}$

In Fig. 10, it is noted that the copper powder prepared at $40 \mathrm{~g} / \mathrm{L} \mathrm{Cu}_{2} \mathrm{O}$ exhibits a much wide mono-modal number distribution and its average size becomes larger, compared to the ones at $20 \mathrm{~g} / \mathrm{L}$ and $30 \mathrm{~g} / \mathrm{L}$. At this high $\mathrm{Cu}_{2} \mathrm{O}$ concentration, the generation rate of $\mathrm{Cu}$ monomers is very high. Fast deposition of $\mathrm{Cu}$ monomer on Pd particles as well as high collision frequency between them in highly concentrated system, of course, might result in uneven growth of particles, rendering the product size and its distribution larger and wider, respectively. 

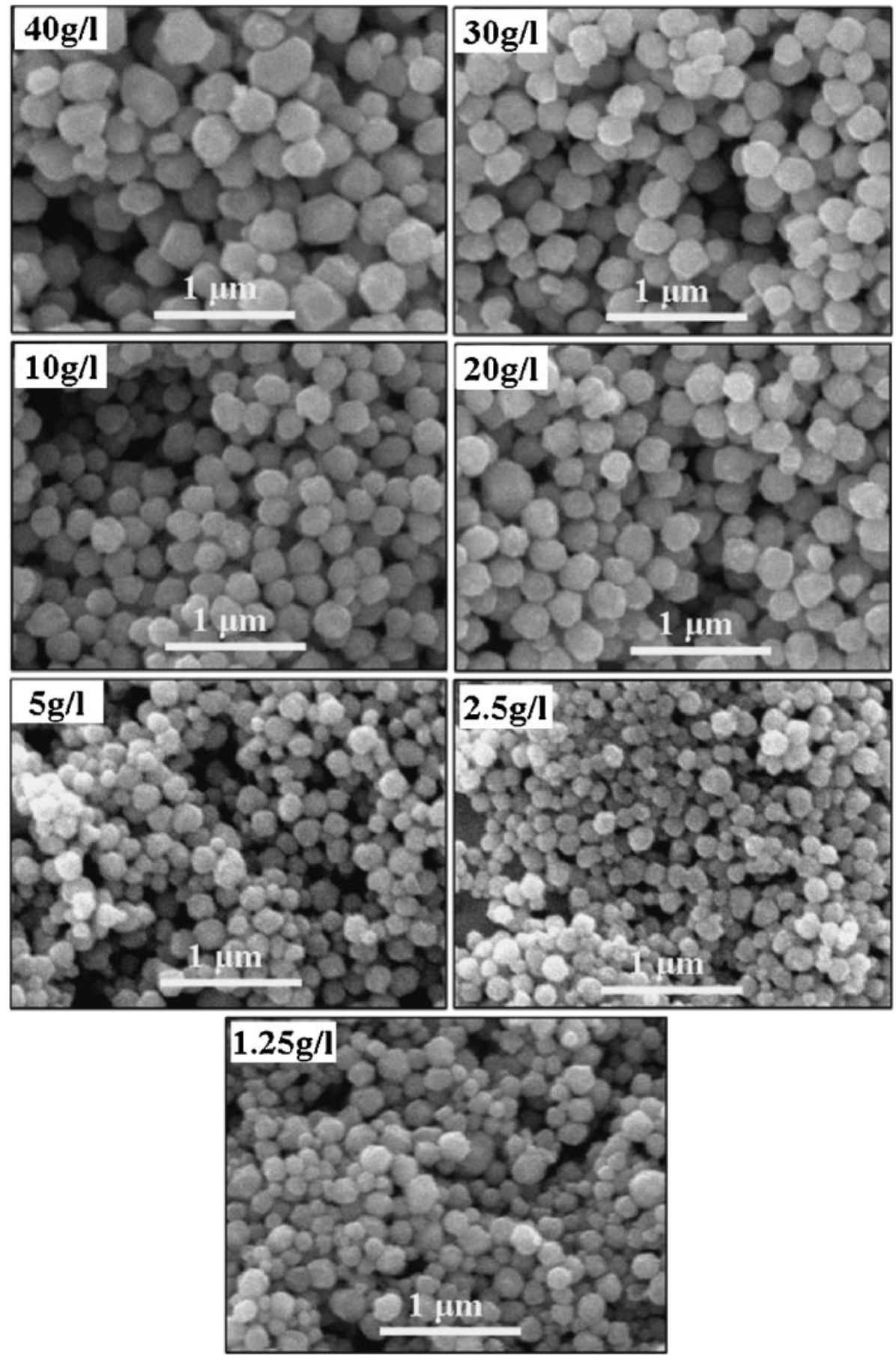

Fig. 7 SEM images of $\mathrm{Cu}$ powders produced at different $\mathrm{Cu}_{2} \mathrm{O}$ concentrations at $333 \mathrm{~K}$.

\section{Conclusions}

Dispersed fine $\mathrm{Cu}$ powders were prepared from the $\mathrm{Cu}_{2} \mathrm{O}$ $\mathrm{H}_{2} \mathrm{O}$ system by a wet chemical reduction technique with hydrazine through a heterogeneous nucleation route. Palladium chloride $\left(\mathrm{PdCl}_{2}\right)$ was used to produce $\mathrm{Pd}$ seed particles with its stabilizer, polyvinyl pyrrolidone and $\mathrm{Na}_{4} \mathrm{O}_{7} \mathrm{P}_{2}$ as a dispersion agent. The conversion rate continuously increased from 313 to $353 \mathrm{~K}$, giving a rise in number of the active Pd particles, thus reducing mean size of the products from 420 to $150 \mathrm{~nm}$, respectively. The powders produced at $313 \mathrm{~K}$ and $323 \mathrm{~K}$ is bi-modal number size distributions because of continuous consumption of Pd particles throughout conver- sion. Whereas at $333 \mathrm{~K}, 343 \mathrm{~K}$ and $353 \mathrm{~K}$ all powders exhibit mono-modal number size distribution, because large number of Pd particles was consumed at the early stages, all particles started to grow at the same point of time.

An increase of $\mathrm{Cu}_{2} \mathrm{O}$ concentration plays strong impact in promoting the $\mathrm{Cu}_{2} \mathrm{O}-\mathrm{Cu}$ conversion rate like that of temperature, thus number of active Pd particles. A decrease of particle size in the range $1.25-2.5 \mathrm{~g} / \mathrm{L} \mathrm{Cu}_{2} \mathrm{O}$ is because the increase of number of active particles is dominant than the increase of $\mathrm{Cu}_{2} \mathrm{O}$ concentration in governing the particle size. In contrarily, in the range $2.5-40 \mathrm{~g} / \mathrm{L}$ the latter is dominant than the former, thus giving a rise of particle size. The explanation for mono-modal size distributions of the powders 


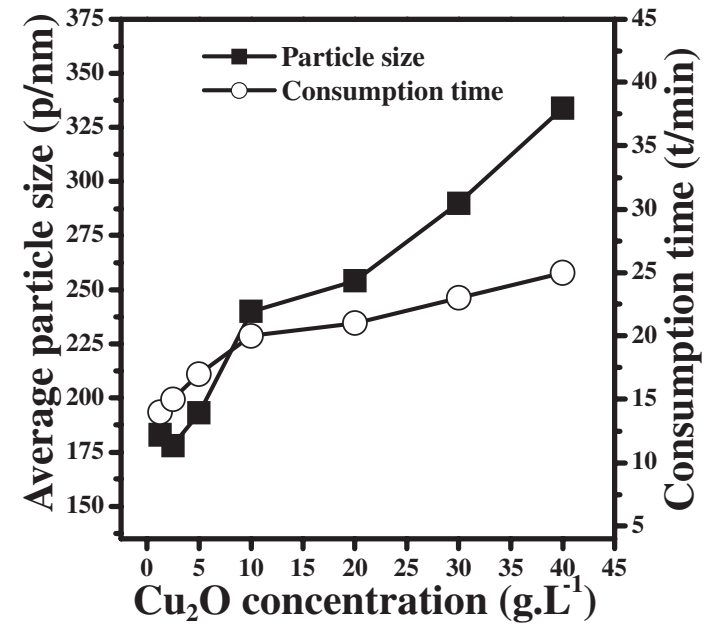

Fig. 8 Average particle sizes and consumption times as a function of $\mathrm{Cu}_{2} \mathrm{O}$ at $333 \mathrm{~K}$.

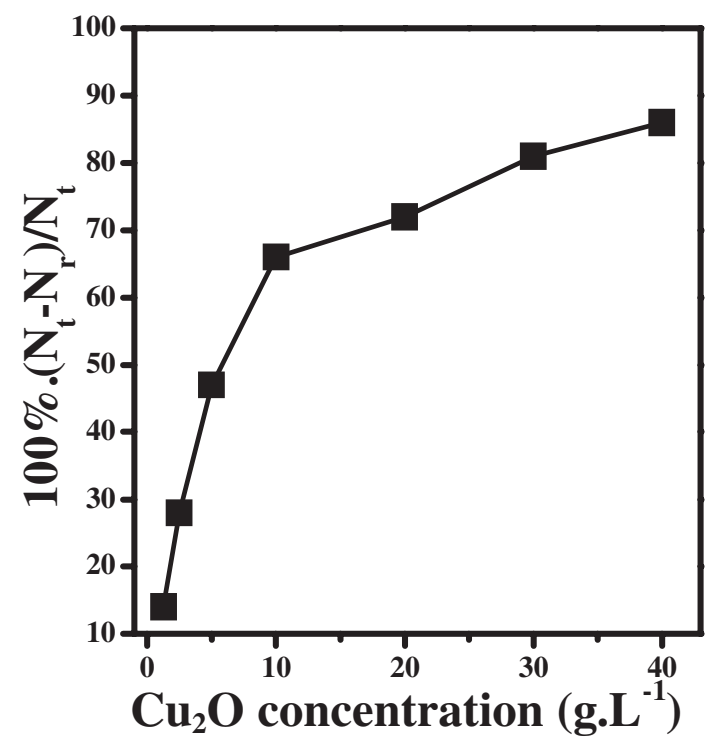

Fig. 9 Weight percentages of active palladium particles as a function of $\mathrm{Cu}_{2} \mathrm{O}$ concentration.

produced in the range $2.5-40 \mathrm{~g} / \mathrm{L}$ is like that for the powders produced at different temperatures in the range 333-353 K, while the explanation for bi-modal size distribution of the powders obtained at $333 \mathrm{~K}$ and $343 \mathrm{~K}$ is appropriate to that produced at $1.25 \mathrm{~g} / \mathrm{L} \mathrm{Cu}_{2} \mathrm{O}$.

\section{Acknowledgments}

This research was supported by the Basic Research Project of the Korea Institute of Geoscience and Mineral Resources (KIGAM) funded by the Ministry of Science and Technology of Korea(MOST).

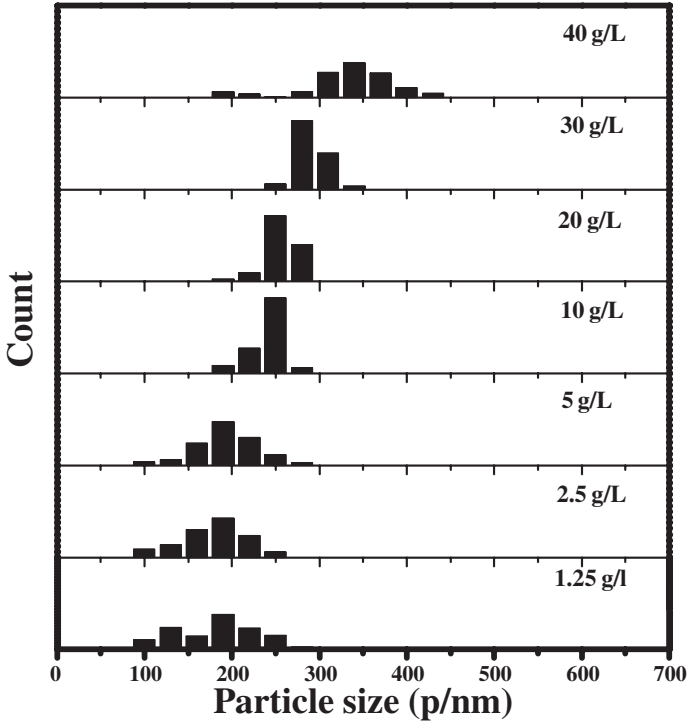

Fig. 10 Number particle size distributions at different $\mathrm{Cu}_{2} \mathrm{O}$ concentrations at $333 \mathrm{~K}$.

\section{REFERENCES}

1) G. S. Whiting, G. L. Bolton, B. R. Sutherland and B. H. Rosof: Advances in Powder Metallurgy and Particulate Materials, A. Lawley, A. Swanson (Eds.), Vol. 1, (Metal Powder Industries Federation, American Powders Metallurgy Institute, NJ, 1993), pp. 107-117.

2) W. Songping and M. Shuyuan: Mater. Let. 60 (2006) 2438-2442.

3) H. Sasaki and T. Naga: Metallurgical Review of MMIJ. 6 (1989) 128138.

4) F. Fievet, J. P. Lagier and M. Figlarz: MRS Bul. December (1989) 2942.

5) J. G. Ahn, H. T. Hai, D. J. Kim, C. O. Kim and H. S. Chung: J. Colloid and Interface Sci. (Under review).

6) Method for collecting inactivated Pd particles from sampled production: Solutions in the products sampled at different times and conditions were decanted by centrifuge at $10.000 \mathrm{rpm}$ during 30 minutes. Nanosized Pd particles of $4 \sim 5 \mathrm{~nm}$ can not be adhered to the wall of centrifugal bottles by this means, thus remain in the decanted solution. Micropipette is used to suck the decanted solution. An aqua regia solution comprising $\mathrm{HCl}$ and $\mathrm{HNO}_{3}$ with volume ratio of $3: 1$ respectively was used to dissolve Pd particles in the solution. At the end, an inductively coupled plasma mass spectrometer (ICP-ELAN 6000) was used to determine concentration of Pd element.

7) S. C. Tjong and H. Chen: Mater. Sci. Eng. R 45 (2004) 1-88.

8) T. Matsoukas and E. Gulari: J. Colloid Interface Sci. 124 (1988) 252261.

9) G. Z. Cao: Nanostructures \& nanomaterials-Synthesis, Properties \& applications (Imperial College Press, 57 Shelton Street, Covent Garden, London, 2004), p. 56.

10) V. K. Lamer and R. H. Dinegar: J. Am. Chem. Soc. 72 (1950) 48474854.

11) V. K. LaMer: Ind. Eng. Chem. 44 (1952) 1270-1277.

12) T. Sugimoto: Adv. Colloid Interface Sci. 28 (1987) 65-108.

13) J. Th. G. Overbeek: Adv. Colloid Interface Sci. 15 (1982) 251-277.

14) F. Fievet, J. P. Lagier, B. Blin, B. Beaudoin and M. Figlarz: Solid State Ionics. 32/33 (1989) 198-205. 